\title{
Targeting heat shock protein 27 (HspBI) interferes with bone metastasis and tumour formation in vivo
}

\author{
B Gibert ${ }^{* 1,2}$, B Eckel $^{3}$, V Gonin ${ }^{3}$, D Goldschneider ${ }^{2}$, J Fombonne ${ }^{2}$, B Deux ${ }^{3}$, P Mehlen ${ }^{2}$, A-P Arrigo², \\ P Clézardin ${ }^{3}$ and C Diaz-Latoud ${ }^{*, 1,3}$
}

'Centre de Génétique Moléculaire et Cellulaire, CNRS UMR5534, Université Lyon I, Université de Lyon, 43 Bd I I Novembre 19I 8, 69622 Villeurbanne Cedex, France; ${ }^{2}$ Apoptosis, Cancer and Development Laboratory- Equipe labellisée 'La Ligue', LabEx DEVweCAN, Centre de Cancérologie de Lyon, INSERM UI052-CNRS UMR5286, Université de Lyon, Centre Léon Bérard, 69008 Lyon, France; ${ }^{3}$ INSERM, UMR I033, LabEx DEVweCAN, Faculté de Médecine RTH Laënnec, Université Lyon I, Université de Lyon, 43 Bd II Novembre 1918, 69622 Villeurbanne, Cedex, France

BACKGROUND: The small stress heat shock protein 27 (Hsp27) has recently turned as a promising target for cancer treatment. Hsp27 upregulation is associated with tumour growth and resistance to chemo- and radio-therapeutic treatments, and several ongoing drugs inhibiting Hsp27 expression are under clinical trial. Hsp27 is now well described to counteract apoptosis and its elevated expression is associated with increased aggressiveness of several primary tumours. However, its role in the later stage of tumour progression and, more specifically, in the later and most deadly stage of tumour metastasis is still unclear.

METHODS/RESULTS: In the present study, we showed by qRT-PCR that Hsp27 gene is overexpressed in a large fraction of the metastatic breast cancer area in 53 patients. We further analysed the role of this protein in mice during bone metastasis invasion and establishment by using Hsp27 genetically depleted MDA-MB23I/B02 human breast cancer cell line as a model. We demonstrate that Hsp27 silencing led to reduced cell migration and invasion in vitro and that in vivo it correlated with a decreased ability of breast cancer cells to metastasise and grow in the skeleton.

CONCLUSION: Altogether, these data characterised Hsp27 as a potent therapeutic target in breast cancer bone metastasis and skeletal tumour growth.

British Journal of Cancer (2012) 107, 63-70. doi:I0.1038/bjc.2012.188 www.bjcancer.com

Published online 24 May 2012

(c) 2012 Cancer Research UK

Keywords: Hsp27; bone; metastasis; apoptosis; therapeutic target; breast

Heat shock protein 27 (Hsp27), also called HspB1, is a member of the human small heat shock protein family characterised by a highly conserved $\alpha$-crystalline domain. This protein has a complex structural organisation that modulates its chaperone activity (Paul et al, 2010). Thus, like other small heat shock proteins, Hsp27 can sequester damaged proteins and prevent their aggregation (Wyttenbach et al, 2002; Arrigo, 2011). This property of molecular sponge leads to increased cell survival, and is correlated with complex patterns of Hsp27 oligomerisation and phosphorylation on three serine residues (Jaya et al, 2009; Paul et al, 2010).

Hsp27 is also well characterised to counteract apoptotic cell death induced by different inducers (Mehlen et al, 1996; Paul et al, 2010). It modulates cell death negatively by blocking the apoptotic cascade at different levels. For example, Hsp27 binds and inactivates cytochrome- $c$ released from mitochondria during apoptotic cell death (Bruey et al, 2000), as well as the pro-domain of procaspase-3, and inhibits the activation process of this caspase, two crucial events for apoptosis execution (Voss et al, 2007). Moreover, Hsp27 is able to directly stabilise actin filaments to protect cell integrity in response to heat, reactive oxygen species, cytotoxic agents (Venkatakrishnan et al, 2006; Pivovarova et al,

\footnotetext{
*Correspondence: Dr B Gibert or Dr C Diaz-Latoud;

E-mail: benjamin.gibert@lyon.unicancer.fr or chantal.diaz@univ-lyon I.fr Received 7 March 2012; revised 3 April 2012; accepted II April 2012; published online 24 May 2012
}

2007) and some apoptotic inducers, as for example staurosporine (Paul et al, 2002, 2010). Hsp27 is also implicated in radio- and chemo-resistance and can negatively modulate cell death induced by anticancerous cytotoxic agents like cisplatin, adriamycin, etoposide or $\gamma$-rays (Zhang and Shen, 2007; Aloy et al, 2008). $\gamma$-Ray resistance may be related to the ability of this protein to counteract oxidative stress (Arrigo, 1998).

In murine vivo models, a direct demonstration of the tumourigenic and metastatic potential of this protein has been done (Garrido et al, 1998; Gibert et al, 2011). Of interest, Hsp27 is highly expressed in many types of human tumours, particularly in those of carcinoma origin, including ovarian, breast, head and neck cancer. Hsp27 overexpression is considered a bad prognostic for patient survival (Ciocca and Calderwood, 2005). This increase in Hsp27 level is probably due to the pro-survival effect of the protein allowing the proliferative potential of cancerous cells in adverse in vivo conditions. All these faculties implicate Hsp27 as a major therapeutic target in cancer (Arrigo et al, 2007; Gibert et al, 2011).

The role and clinical outcome of Hsp27 in primary tumours has been well studied and documented (Ciocca and Calderwood, 2005; Calderwood et al, 2006; Tsuruta et al, 2008; Huang et al, 2010). However, its function in metastasis invasion has been less studied, even though Hsp27 gene has been shown by proteomic analysis to be overexpressed in tumour cells of patients that are able to metastasise (Song et al, 2006; Tian et al, 2007). It is also interesting to note that surface expression of murine Hsp27 stimulates tumour growth and metastasis of the highly metastatic murine $4 \mathrm{~T} 1$ breast 
adenocarcinoma cells, whereas silencing of this protein eliminates migration capability (Bausero et al, 2004; Kaur et al, 2011). In the present study, we showed that Hsp27 is overexpressed in tumours that are able to metastasise, in 53 human breast cancer patients. We further investigated the role of human Hsp27 during bone metastasis formation and tumour growth in mice. Bone metastasis invasion is very often a dramatic stage of tumour progression, which frequently occurs and generally leads to patient death. Bone metastases in breast cancer patients are also associated with bone destruction that correlates with hypercalcaemia and fractures.

We used the breast MDA-MB231/B02 metastatic cell line as a model to analyse the effect of Hsp27 silencing (Pecheur et al, 2002; Peyruchaud et al, 2003). This cell line displays a unique tropism for bone dissemination and constitutively expresses a high level of Hsp27. The aim of this work was to investigate the role of Hsp27 in bone colonisation by breast cancer cells. We provide here experimental evidence for a role of $\mathrm{Hsp} 27$ in migration and invasion of bone tissue by metastatic breast cancer cells.

\section{MATERIALS AND METHODS}

\section{Cell culture and transfections}

The MDA-MB-231/B02 luciferase human breast cancer cell line is a subpopulation of the MDA-MB-231 cancer cell line that was selected for its high efficiency to metastasise to bones after intravenous inoculation (Pecheur et al, 2002; Peyruchaud et al, 2003).

All cells were grown at $37^{\circ} \mathrm{C}$ in a humidified atmosphere containing 5\% $\mathrm{CO}_{2}$. MDA-MD231/B02 cells were grown in Dulbecco's modified Eagle's medium supplemented with $10 \%$ heat-inactivated fetal calf serum. Cells were transfected according to the jet prime reagent procedure (Poly plus transfection, Pontoise, France). For transient transfection assays, DNA vector was left on cells for $6 \mathrm{~h}$; thereafter, cells were washed with phosphate-buffered saline before being further incubated in fresh medium.

\section{Gel electrophoresis and immunoblotting}

Cultured cells were immediately rinsed twice in ice-cold phosphate-buffered saline and scraped off the dish. At this point, aliquots were withdrawn for determination of protein concentration. Thereafter, cells were directly lysed and denatured in SDS buffer $(62.5 \mathrm{~mm}$ Tris- $\mathrm{HCl}, \mathrm{pH} 6.8 ; 0.1 \mathrm{~m}$ dithioerythritol; $1 \%$ SDS; $0.001 \%$ bromophenol blue; and $10 \%$ glycerol). Cell lysates were subjected to SDS-polyacrylamide gel electrophoresis (SDSPAGE) performed as previously described (Javouhey et al, 2008). Immunoblots probed with different specific antibodies were revealed with the ECL system (Amersham Life Science, Pantin, France). Autoradiographs were recorded on X-Omat LS films (Eastman Kodak Co, Rochester, NY, USA).

\section{ShRNA construction}

The pCIstricke plasmid (Promega, Charbonnières, France) was used for DNA vector-based shRNA construction. The Hsp27 targeting sequence of the designed oligonucleotides was $5^{\prime}$-GCTGCAAAATCCGATGAG-3'. After annealing, ligation and transformation of the resulting DNA vector into competent DH5 $\alpha$ bacteria (Invitrogen, Cergy Pontoise, France), antibiotic resistance was used to select the positive bacterial colonies. The correct sequences of the final DNA preparations for pCIstrike-ShRNA27 (Sh27) were confirmed by sequencing (GenomExpress, Meylan, France). pCIstrike-MsRNA27 (Ms27) vectors were designed as a degenerated control from the above sequence of pCIstrikeShRNA27.

\section{Generation of stable MDA-MB231/B02 cells containing reduced levels of $\mathrm{Hsp} 27$}

Four cell culture dishes were seeded at $1 \times 10^{6}$ cells per $78 \mathrm{~cm}^{2}$. Transfection of MDA-MB231/B02 luciferase (B02) cells was performed with pCIstrike-ShRNA27 or pCIstrike-MsRNA27 DNA vector (Pecheur et al, 2002; Peyruchaud et al, 2003). One day later, B02 cells were incubated in the presence of neomycin at a concentration of $1 \mathrm{mg} \mathrm{ml}^{-1}$. Neomycin-resistant clones were tested for their Hsp27 levels by western blot. Three independent clones expressing minimal endogenous Hsp27 (named: B02-Sh27) and three independent control clones expressing normal levels of Hsp27 (named: B02-Ms27) were selected, propagated and further analysed.

\section{Determination of cellular proliferation}

Cell proliferation was determined using the WST-1 test (Promega, Charbonnières, France). The B02 cells were seeded in 96-well plates $\left(7.5 \times 10^{3}\right.$ per well), incubated with $10 \mu \mathrm{l}$ per well for $4 \mathrm{~h}$ in tetrazolium WST-1 salt (4-[3-(4-iodophenyl)-2-(4-bonitrophenyl)$2 \mathrm{H}$-5-tetrazolio]-1,3-benzene disulphonate) and followed by absorbance measurement at $450 \mathrm{~nm}$ with a Wallac 1420 Multilabel Counter (PerkinElmer, Courtabœuf, France). The percentage of cellular proliferation was calculated based on a control absorbance.

\section{Chemotaxis assay}

Cell migration and invasion assays were performed in 24-well cell culture chambers with 8 - $\mu \mathrm{m}$-diameter pore-size inserts (Becton Dickinson, Pont de Claix, France), as previously described (Zhao et al, 2007). Inserts were coated with $100 \mu$ l basement membrane Matrigel ( $3 \mu \mathrm{g} \mathrm{ml}{ }^{-1}$; Becton Dickinson) for $90 \mathrm{~min}$ at $37^{\circ} \mathrm{C}$ in order to perform cell invasion experiments. B02 cancer cells $\left(1.5 \times 10^{5}\right.$ cells per ml) were re-suspended in Dulbecco's modified Eagle's medium containing $0.1 \%(\mathrm{w} / \mathrm{v})$ bovine serum albumin, and $300 \mu \mathrm{l}$ of this cell suspension was loaded into each insert (upper chamber). The chemo-attractant $(10 \%(\mathrm{v} / \mathrm{v})$ fetal calf serum) was placed in the lower chamber $(750 \mu \mathrm{l}$ per well). The plates were incubated for $6 \mathrm{~h}$ at $37^{\circ} \mathrm{C}$ in a $5 \% \mathrm{CO}_{2}$ incubator. After incubation, the inserts were collected carefully, the non-migrating cells were removed, and the migrating cells on the under-surface of the inserts were fixed and stained with crystal violet. The membranes were mounted on glass slides and cells were counted under microscope.

\section{Animal studies}

Animal studies were performed according to ethics recommendations and animal welfare (Workman et al, 2010). Bone metastasis experiments were conducted in Nude mice, as described previously (Pecheur et al, 2002; Peyruchaud et al, 2003; Zhao et al, 2007). MDA-MB-231/B02 cells that had been stably transfected with shRNAs directed against Hsp27 or control mismatches $\left(5 \times 10^{5}\right.$ in $100 \mu \mathrm{l}$ of phosphate-buffered saline) were injected into the tail vein of nude mice anaesthetised with $130 \mathrm{mg} / \mathrm{kg}$ ketamin and $8.8 \mathrm{mg} \mathrm{kg}^{-1}$ xylazin. Radiographs of anaesthetised animals were taken weekly with the use of MIN-R2000 films (Eastman Kodak Co) in an MX-20 cabinet X-ray system (Faxitron X-ray Corporation, Wheeling, IL, USA). Osteolytic lesions were identified on radiographs as radiolucent lesions in the bone. The area of osteolytic lesions was measured using a Visiolab 2000 computerised image analysis system (Explora Nova, La Rochelle, France), and the extent of bone destruction per leg was expressed in square millimetres. Anaesthetised mice were killed by cervical dislocation after radiography on day 28 (Workman et al, 2010).

Intra-osseous tumour xenograft experiments were conducted in nude mice, as described previously (Zhao et al, 2007). Briefly, 
a small hole was drilled with a 30 -gauge sterile needle through the tibial plateau with the knee flexed. Using a new sterile needle fitted to a 50- $\mu$ l sterile Hamilton syringe (Hamilton Co., Reno, NV, USA), a single-cell suspension $\left(1 \times 10^{5}\right.$ cells in $30 \mu$ l of phosphatebuffered saline) was injected into the bone marrow cavity. The progression of osteolytic lesions was monitored by radiography as described above (Zhao et al, 2007). Anaesthetised animals were killed by cervical dislocation 7 weeks after tumour cell inoculation.

\section{Bone histology and histomorphometry}

Bone histology and histomorphometry analysis of bone lesions were performed as previously described (Pecheur et al, 2002; Peyruchaud et al, 2003; Zhao et al, 2007). Following killing of metastatic animals, both hind limbs from each animal were dissected, fixed in $80 \%(\mathrm{v} / \mathrm{v})$ alcohol, dehydrated and embedded in methylmethacrylate. A microtome (Microm, Micron Microtech, Francheville, France, HM350S) was used to cut $7-9-\mu \mathrm{m}$ thick sections of undecalcified long bones, and the sections were stained with Goldner's trichrome. Histologic and histomorphometric analyses were performed on Goldner's trichrome-stained longitudinal medial sections of the tibial metaphysis using a computerised image analysis system (Visiolab 2000, Explora Nova). Histomorphometric measurements (i.e., bone volume/tissue volume (BV/TV) and tumour burden/ soft tissue volume (TB/ STV) ratios) were performed in a standard zone of the tibial metaphysis, situated at $0.5 \mathrm{~mm}$ distance from the growth plate, including cortical and trabecular bone. The BV/TV ratio represents the percentage of bone tissue. The TV/STV ratio represents the percentage of tumour tissue.

\section{Statistics}

The statistical significance of differences between groups was evaluated by the Mann-Whitney $U$-test. All statistical tests were two-sided, and $P$ values $<0.05$ were considered to be statistically significant: ${ }^{\star} P<0.05,{ }^{*} P<0.01$.

\section{Human breast tumour samples, quantitative PCR}

Fifty-three human breast cancer samples were provided by the tumour bank of the Centre Léon Bérard after obtaining patients' consent. Fresh tissue of the tumour was obtained during breast surgery before any systemic therapy and snap-frozen in liquid nitrogen. To assay Hsp27 expression, total RNA was extracted from samples with the Nucleospin RNAII kit (Macherey-Nagel, Düren, Germany) and $1 \mu \mathrm{g}$ of RNA was reverse transcribed using the iScript cDNA Synthesis kit (Bio-Rad, Hercules, CA, USA). Realtime qRT-PCR was performed on a LightCycler 2.0 using the LightCycler TaqMan Master kit (Roche Applied Science, Basel, Switzerland) according to the manufacturer's instructions. The ubiquitously expressed TBP gene was used as internal control and the same results have been confirmed with HPRT and HMBS genes (de Kok et al, 2005). Primers and probe were given by Universal Probe Library Assay Design Center website and are available upon request (Roche Applied Science). All patient tissue specimens were used according to French laws and regulations.

\section{RESULTS}

\section{Hsp27 is a marker for human metastatic breast cancer}

We first analysed Hsp27 expression by quantitative-PCR in a panel of 53 human breast primary tumours (Figure 1A). These tumours were from lymph node-negative patients (M0-N0, 13 patients), lymph node-positive patients (M0-N1, 29 patients) or metastatic patients at the time of diagnosis (M1, 11 patients). Hsp27 is significantly more expressed in M0-N1 tumours than in M0-N0 tumours (median 2.95 vs 6.85; $P=0.0119$ ). An even more striking

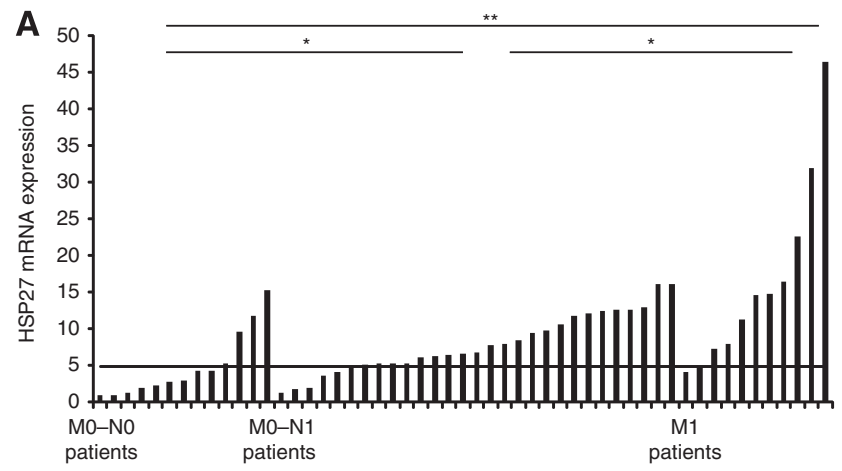

\begin{tabular}{|c|c|c|c|}
\cline { 2 - 4 } \multicolumn{1}{l|}{} & M0 N0 & M0 N1 & M1 \\
\hline $\begin{array}{c}\text { Hsp27 median } \\
\text { expression }\end{array}$ & 1 & 2.57 & 2.95 \\
\hline $\begin{array}{c}\text { Hsp27 } \\
\text { overexpression }\end{array}$ & $30.80 \%$ & $79.30 \%$ & $90.90 \%$ \\
\hline
\end{tabular}

Figure I Hsp27 relative expression in metastatic breast tumours. (A) Expression profile of $\mathrm{Hsp} 27$ examined by quantitative real-time PCR by using mRNA extracted from 53 tumour biopsy specimens were obtained from patients with tumours localised to the breast (MO-NO), with only node involvement (MO-NI), and with distant

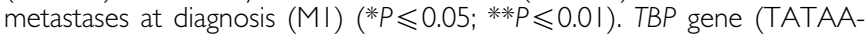
box-binding protein) was used as a reference here because it shows a weak variability in the breast (de Kok et al, 2005). Identical results were obtained with HBMS and HPRT housekeeping genes. (B) Hsp27 expression is given as the ratio between $\mathrm{Hsp} 27$ expression in each sample and the average of Hsp27 expression in the M0-NO samples, shown by a horizontal bar in ( $\mathbf{A})$. Hsp27 overexpression: percentages of MO-N0, MO-NI and MI of samples showing a superior average as compared with the M0-N0 group average.

difference is observed when comparing Hsp27 expression in M0-N0 with that in M1 tumours (median 2.95 vs 14.58; $P=0.0019)$. A significant difference exists between $\mathrm{M} 0-\mathrm{N} 1$ and M1 (median 6.85 vs 14.58; $P=0.026$ ). As shown in Figure $1 \mathrm{~B}$, Hsp27 is overexpressed in $79.30 \%$ of patients in the M0-N1 and $90.90 \%$ in the M1 group (based on the average of the M0-N0 group). Altogether, these data prove that Hsp27 is a marker of the aggressive forms of human breast tumours, especially the metastatic ones.

\section{Establishment of Hsp27-depleted clones}

The human breast cancer cell line MDA-MB231 is a wellcharacterised model of metastasis invasion in vivo. To assess the role of Hsp27 in breast cancer metastasis, we used a sub-clone of this cell line, called MDA-MB231/B02 (B02), that has been characterised to specifically metastasise in the bone marrow and not in other tissues when injected in mice (Pecheur et al, 2002; Peyruchaud et al, 2003). This cell line can be efficiently tracked in vivo and its metastatic aggressiveness could be quantified easily by radiographies. We first compared Hsp27 levels in B02 and parental MDA-MB231. These cells have rather similar levels of

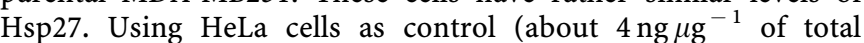
proteins; Paul et al, 2010), their Hsp27 level was estimated at about $3 \mathrm{ng} \mu \mathrm{g}^{-1}$. B02 cells expressed almost the same Hsp27 level as parental cells (Figure 2A). The fact that Hsp27 expression level is similar between MDA-MB231 and B02 cells suggests that Hsp27 expression is not related to B02 cells' osteotropism.

To investigate the pro-oncogenic role of $\mathrm{Hsp} 27$ during metastasis process, we established independent clones of B02 cells transfected with shRNA directed against Hsp27 or with mismatches of shRNA. Assessment of Hsp27 levels in B02 cells, by western blotting analysis, revealed a 90\% inhibition of Hsp27 protein expression in hsp27 shRNA-transfected clones (Figure 2B). 
A

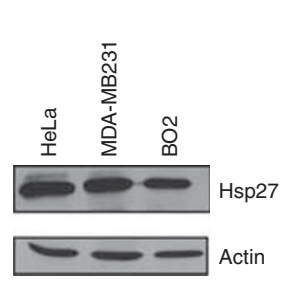

C

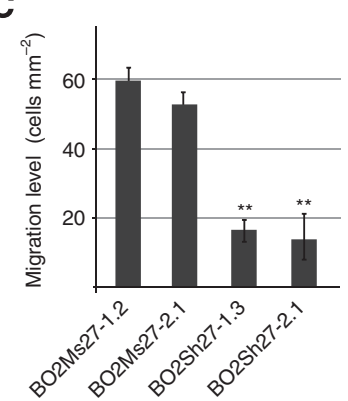

B

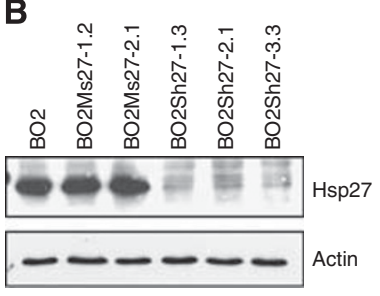

D

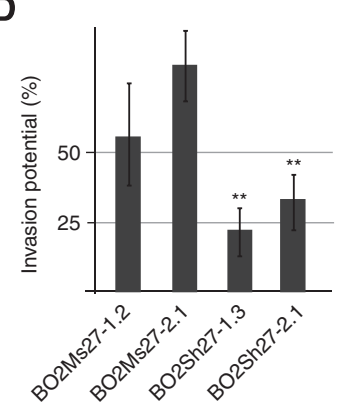

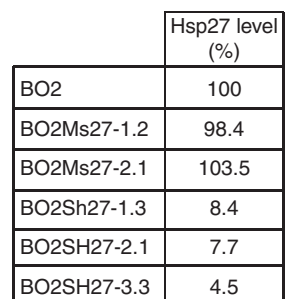

E

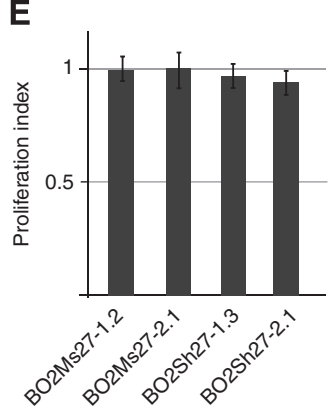

Figure 2 Characterisation of Hsp27-depleted B02 clones. (A) HeLa, MDA-MB23I and MDA-MB23I B02 (B02) cells were cultured as described in Materials and Methods. Samples were collected $48 \mathrm{~h}$ after transfection and Hsp27 level was analysed by western blot. Level of actin was used as a loading control. (B) pClstrike-MsRNA27 (Ms27) and pClstrike-ShRNA27 (Sh27) vectors were constitutively expressed in B02 cells. Immunoblots were revealed by the corresponding antibodies. (C) Hsp27 depletion reduces migration and invasion potential but not proliferation of B02 cells. The modified Boyden chamber technique was used for cell migration assessment. B02 cells were cultured without serum in the insert chambers with pore inserts. Cells able to migrate through the membrane were stained with crystal violet and counted (** $P \leqslant 0.0$ I). (D) Invasiveness of cells was studied by addition of a Matrigel layer in the upper chambers, and like in the migration assay, clones were quantified as described in Materials and Methods (*** $\leqslant \leqslant 0.0 \mathrm{I}$ ). (E) WST-I tests were performed every $12 \mathrm{~h}$ during 5 days. Proliferation index was determined and reported for each clone.

Two shRNA clones, as well as two negative control mismatch clones, were selected for further studies.

\section{Hsp27 silencing inhibits both cellular migration and invasion but not proliferation}

Metastatic tumour cells usually show enhanced migratory capacity and this is often associated with a decreased adhesion. In order to determine whether Hsp27 downregulation could impact this mechanism, we tested the cellular migration of the genetically modified B02 cell clones by performing chemotaxis assays in cell culture chambers with pore inserts. As shown in Figure 2C, migration of Hsp27-depleted cells was dramatically reduced down to $70 \%$ as compared with control scramble cells $(P \leqslant 0.01)$.

Invasion of tumour cells into surrounding tissues is also known as a crucial event leading to development of distant metastases. Therefore, we evaluated the invasion potential using inserts that were coated with Matrigel basement membrane to evaluate whether matrix degradation was occurring. Matrix invasion by Hsp27-depleted clones was significantly decreased compared with control cells (Figure 2D), but in the same proportions as in the migration assay performed without Matrigel, suggesting that Hsp27 depletion does not affect the ability of B02 cells to degrade Matrigel.

In addition, we have tested the effect of Hsp27 downregulation on cellular proliferation state (Park et al, 2002; Lee et al, 2004). In previous studies using HeLa cells, we have shown that Hsp27 depletion decreased proliferation by interfering with $G_{2} / M$ phase (Gibert et al, 2012). In contrast, analysis of the WST-1 proliferation assay of B02 cells revealed that Hsp27 depletion was devoid of significant effect (Figure 2D).

\section{Hsp27 inhibition of expression reduces metastasis formation in vivo}

Metastasis invasion is correlated with the transport of cancer cells by a circulatory system to distant sites. We next wanted to assess whether the Hsp27 depletion in B02 cells inhibited bone metastasis formation in vivo. Pools of $\mathrm{B} 02-\mathrm{Sh} 27$ or $\mathrm{B} 02-\mathrm{Ms} 27$ clones were therefore injected in anaesthetised nude mice by intravenous injection in the tail. B02 cells have been transfected to stably express a luciferase enzyme, which allows in vivo B02 cell detection by injection of luciferin. Luciferase activity as bioluminescence was then quantified. It correlated with metastasis expansion and dissemination, and was represented by an indicative colouration inlay in mice pictures (Figure 3A). Metastasis development was only detected in the bone marrow thigh of mice, confirming the specificity of B02 cells to form bone metastasis in vivo, in contrast to the MDA-MB-231 parental cells. Luciferase activity was statistically decreased by about $50 \%$ during the first 3 weeks $(P \leqslant 0.01)$ in the group of B02-Sh27-inoculated mice as compared with the ones injected with B02-Ms27 cells. These results suggest that Hsp27 depletion delays metastasis formation by B02 cells (Figure 3B).

Bone metastasis progression is highly correlated with bone demineralisation and fractures due to cancer progression in this environment. Hence, in addition to the in vivo analysis of B02 cells' luciferase activity described above, radiographies of each mouse were performed to analyse metastasis expansion. Measurement of osteolytic lesions was achieved by quantification of bone destruction on hind limb radiograph (Figure 4A). As shown in Figure 4C, the extent of osteolytic lesions was dramatically decreased when animals were injected with B02 cells depleted in Hsp27 compared with control cells. There was a significant difference between the groups during all the experiments, including at day 28, when the luciferase activity was similar between mice injected with B02-Sh27 and those injected with B02-Ms27 cells.

Histomorphometric studies were performed at day 28 in order to quantify bone destruction and tumour burden in the animals. Similar to quantitative-PCR on tumour biopsies, Sh27 still invalidated Hsp27 expression after 4 weeks of xenografts (Supplementary Figure 1). As shown in Figure 4C, the results confirm that bone destruction is diminished in animals injected with Hsp27-depleted B02 cells compared with control B02-Ms27 
A

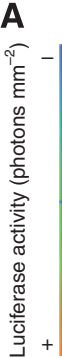

Day 7
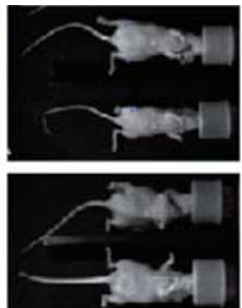

Day 14
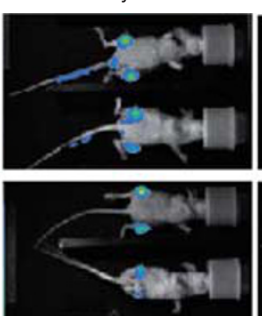

Day 21
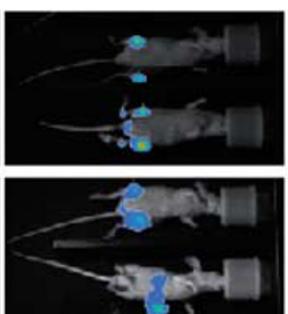

Day 28

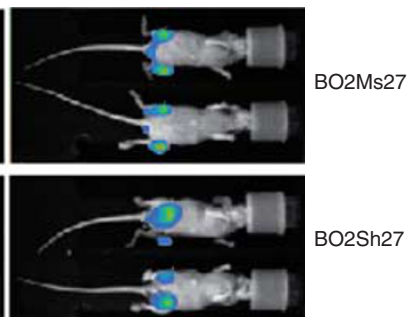

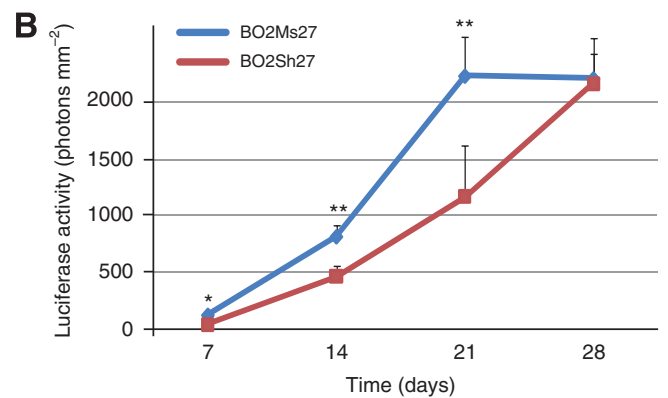

Figure 3 Effect of Hsp27 silencing on breast cancer bone metastasis formation in animals. B02Ms27 cells and cells silenced for Hsp27 expression (B02Sh27) were injected intravenously into nude mice. (A) Luciferase activity is quantified weekly using the night owl technology, as described in Materials and Methods, after a subcutaneous injection of luciferin. Luciferase activity is inlaid in the mice picture with the corresponding ladder. (B) Luciferase expression, weekly quantified in $\mathrm{B} 02-\mathrm{SH} 27$ clones and control cells, is reported in the graph. (**P $\leqslant 0.0 \mathrm{I})$.
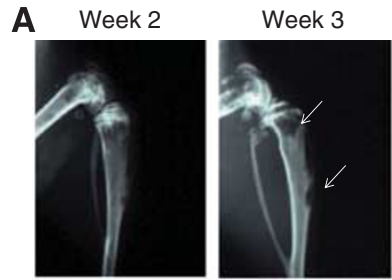

Week 4
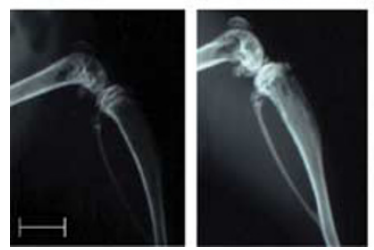

C

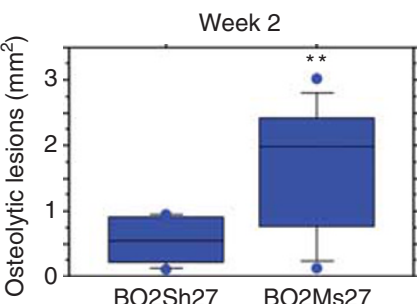

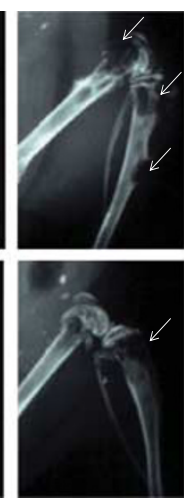

B

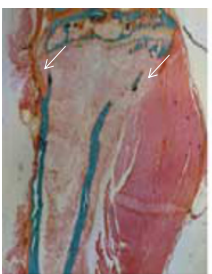

BO2Sh27

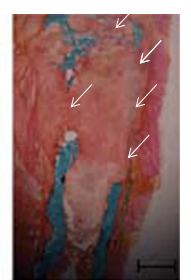

BO2Ms27

BO2Sh27

\begin{tabular}{|c|c|c|}
\cline { 2 - 3 } \multicolumn{1}{c|}{ Histomorphometry } & BV/TV (in \%) & TB/STV (in \%) \\
\hline BO2-Sh27 & $23.5 \pm 4.1^{*}$ & $26.5 \pm 6.0^{*}$ \\
\hline BO2-Ms27 & $9.4 \pm 3.2$ & $40.7 \pm 11.8$ \\
\hline
\end{tabular}
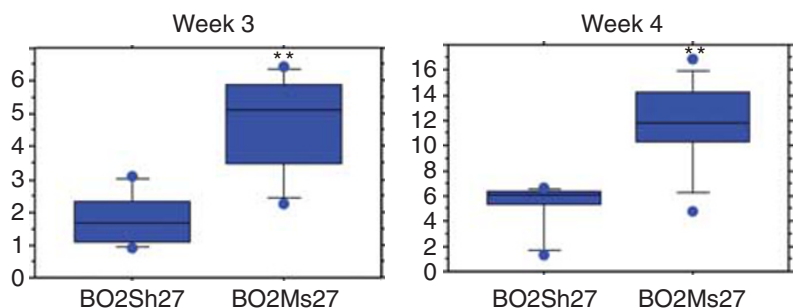

Figure 4 Effect of Hsp27 depletion on bone lesion formation. Radiographic, immunostaining and histomorphometric data were obtained on day 3 I after tumour cell inoculation in nude mice. (A) Osteolytic lesions on representative radiographs are indicated by white arrows. Scale bar $=0.5 \mathrm{~cm}$. (B) Representative bone histology of Goldner's trichrome-stained tibial metaphysis from metastatic animals. The bone is coloured in green; bone marrow and tumour cells are coloured in red. Scale bar $=0.5 \mathrm{~mm}$. BV/TV: bone volume relative to tissue volume. TB/STV: skeletal tumour burden relative to soft tissue volume ratio (arrows: bone decalcification) $(* * P \leqslant 0.0$ I). (C) Bone decalcification was quantified by software using Visiolab 2000 , and the results are reported in the graph $(* * * \leqslant 0.01)$.

cells. It should be noted that trabecular bone was only partially destroyed in tibiae of mice injected with B02-Sh27 cells $(\mathrm{BV} / \mathrm{TV}=23.5 \%$; $\mathrm{TB} / \mathrm{STV}=26.5 \%)$, whereas it had completely disappeared in the metaphysic tibiae of animals injected with B02-Ms27 cells $(\mathrm{BV} / \mathrm{TV}=9.4 \%$; $\mathrm{TB} / \mathrm{STV}=40.0 \%)$.
This study also showed that at day 28, Sh27 tumour size is dramatically decreased in comparison with Ms27 tumours. This result is not in accord with the luciferase activity measured in these animals (see above; Figure 3), a discrepancy that could be the result of the fact that at day 28 the large size of the tumours 

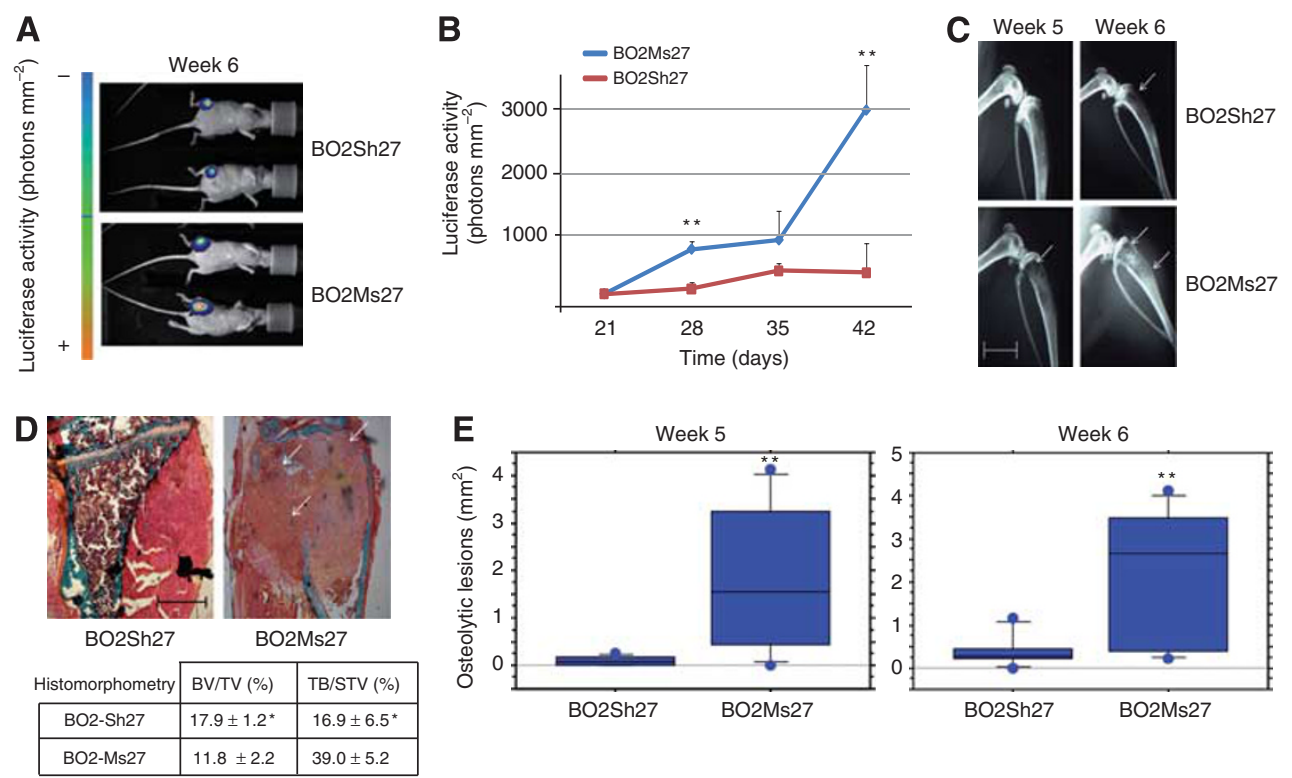

Figure 5 Hsp27 depletion decreases tumour formation in bone. B02-Ms27 cells and B02-Sh27 cells were injected in the left tibiae of female nude mice $(* * * 0.01)$. (A) Luciferase activity was quantified using the night owl technology as described in Materials and Methods. Photographs presented are representative of the results for each animal group. (B) Luciferase activity was measured weekly during 2 months and are reported on graph. (C) Bone lesions were weekly quantified by radiography of the injected tibiae. Demineralisation is depicted with white arrows. Scale bar=0.5mm. (D) Histomorphometric data of tibiae were obtained 2 months after cell inoculation. The bone is coloured in green, whereas bone marrow and tumour cells (stars) are coloured in red. BV/TV: bone volume relative to tissue volume. TB/STV: skeletal tumour burden relative to soft tissue volume ratio. Scale bar $=0.5 \mathrm{~mm}$ (arrows: bone decalcification). (E) Quantification of osteolysis is performed on radiographs and is presented in a graph for each group of mice.

interfered with luciferase bioluminescence activity, which was then not precise enough to detect the differences observed in the histomorphometric study (El Hilali et al, 2002).

\section{Hsp27 depletion inhibits bone tumour formation}

In order to determine whether the decrease in bone metastasis formation observed in response to Hsp27 inhibition was only due to the inhibition of migration and invasion of the cells, we next injected the cells directly into the tibiae of nude mice. In this experiment, most of the mechanisms of migration could be ignored because the cells were already on the metastatic site. Xenograft development was evaluated weekly during 2 months by bioluminescence quantification and radiography. Luminescence activity was only detected in the injected tibiae, showing that the cells once injected in the tibiae did not disseminate in the organism (Figure 5A). Quantification of luciferase activity revealed a decrease in tumour burden in animals injected with B02 cells depleted of Hsp27 (Figure 5B). Therefore, this result was confirmed by histomorphometric analysis. Osteolytic lesions were also dramatically reduced in case of the inhibition of Hsp27, as also confirmed by histomorphometric analysis (Figure 5C and D). Moreover, quantification of bone destruction confirmed that osteolytic lesions were reduced after injection of the B02-Sh27 $(\mathrm{BV} / \mathrm{TV}=23.5 \%$; $\mathrm{TB} / \mathrm{STV}=23.5 \%)$ cells compared with the $\mathrm{B} 02$ Ms27 cells $(\mathrm{BV} / \mathrm{TV}=9.4 \%$; $\mathrm{TB} / \mathrm{STV}=40.7 \%)$.

Taken together, these experiments show that Hsp27 is not only important for increased migration and invasion properties of metastatic cancer cell, but it also has a major role in formation of the metastatic lesion per se at the secondary bone settings.

\section{DISCUSSION}

Hsp27 has been shown to be a major therapeutic target for cancer therapies against primary tumour formation by protecting cells against apoptosis. This stress protein is upregulated in many tumour types, including breast, ovarian, colon, head and neck cancer (Ciocca and Calderwood, 2005; Calderwood et al, 2006; Tsuruta et al, 2008; Huang et al, 2010), but was not well characterised during in vivo metastasis development. In our study, we show that Hsp27 is overexpressed in the aggressive forms of 53 human breast tumours. Thus, in tumours positive for lymph node invasion, the increase is 2.57 -fold over the median expression, whereas it is 2.95 -fold over the median in the metastatic ones (Figure 1A). This increased expression may have some correlation with the results presented in a recent study highlighting the role of Hsp27 in epithelial-mesenchymal transition (Wei et al, 2011).

To understand whether this overexpression is important in the development of metastasis in distant organs, we analysed the consequences of Hsp27 silencing in a mice xenograft model. We used the breast cancer cell line MDA-MB231/B02, characterised for its tropism for bone invasion (Pecheur et al, 2002). In breast cancer, bone metastases have been correlated with bone alterationlike demineralisation and fractures. The role of Hsp27 in breast cancer metastases, particularly in bone metastasis, is not clearly elucidated. We show here using two different techniques that Hsp27 silencing induces a decrease in metastasis formation (Figure 3 and 4). Luminescence detection was highly correlated with bone decalcification as revealed by radiographies, except in one case (at day 28, Figure $3 \mathrm{~A}$ ), probably because luciferase activity is altered in important metastases, leading to quantification defects as proven by other studies (El Hilali et al, 2002; Paroo et al, 2004).

Lemieux et al (1999) have shown that overexpression of Hsp27 leads to a decrease in cellular migration of MDA-MB231 cells, and that in the MDA-MB231 cells, overexpression of Hsp27 did not show a significant effect on bone dissemination and alteration in vivo. In our study, we silenced the expression of Hsp27 using a ShRNA approach and we characterised clones presenting a decrease of about $90 \%$ in Hsp27 expression. These depleted clones showed a decreased ability to migrate and invade in vitro. 
Hence, it can be concluded that a decrease in bone metastasis formation can be observed following a depletion (our study) or overexpression (Lemieux et al, 1999) of Hsp27. These apparently conflicting results may suggest that the intracellular level of Hsp27 has a crucial role in this phenomenon. Consequently, a negative or positive change in Hsp27 balance level may alter the heterogenic structures formed by this protein (Paul et al, 2010) and destabilise its interactions with pro-metastatic client protein targets. In this regard, Hsp27 has been shown to stabilise F-actin filaments during cell migration (Pivovarova et al, 2007; Lee et al, 2008; Chen et al, 2009), confirming our results obtained with antisense strategy. Overexpression of Hsp27 could also have drastic effects on cytoskeleton architecture that may also lead to a decreased ability of cells to migrate. Future experiments are needed to test this hypothesis.

Our results also suggest that the decrease in cellular migration and invasion are not the only mechanisms responsible for the low level of bone metastasis formation. Indeed, we have observed that silencing of Hsp27 is associated with a decreased amount of tumour cells in the bone microenvironment (Figure 5). One possible hint for the effect is the fact that it is known that the bone microenvironment is a very stressful environment, owing mostly to intense mechanical stresses. We have previously shown that Hsp27 functional inhibition, by interfering peptides called aptamers, could modify the in vivo proliferation of tumours, whereas proliferation was not modified in cell culture conditions

\section{REFERENCES}

Aloy MT, Hadchity E, Bionda C, Diaz-Latoud C, Claude L, Rousson R, Arrigo AP, Rodriguez-Lafrasse C (2008) Protective role of Hsp27 protein against gamma radiation-induced apoptosis and radiosensitization effects of Hsp27 gene silencing in different human tumor cells. Int J Radiat Oncol Biol Phys 70: 543-553

Arrigo AP (1998) Small stress proteins: chaperones that act as regulators of intracellular redox state and programmed cell death. Biol Chem 379: $19-26$

Arrigo AP (2011) Structure-functions of HspB1 (Hsp27). Methods Mol Biol 787: $105-119$

Arrigo AP, Simon S, Gibert B, Kretz-Remy C, Nivon M, Czekalla A, Guillet D, Moulin M, Diaz-Latoud C, Vicart P (2007) Hsp27 (HspB1) and alphaB-crystallin (HspB5) as therapeutic targets. FEBS Lett 581: 3665-3674

Bausero MA, Page DT, Osinaga E, Asea A (2004) Surface expression of Hsp25 and Hsp72 differentially regulates tumor growth and metastasis. Tumour Biol 25: 243-251

Bruey JM, Ducasse C, Bonniaud P, Ravagnan L, Susin SA, Diaz-Latoud C, Gurbuxani S, Arrigo AP, Kroemer G, Solary E, Garrido C (2000) Hsp27 negatively regulates cell death by interacting with cytochrome c. Nat Cell Biol 2: 645-652

Calderwood SK, Khaleque MA, Sawyer DB, Ciocca DR (2006) Heat shock proteins in cancer: chaperones of tumorigenesis. Trends Biochem Sci 31: $164-172$

Chen HF, Xie LD, Xu CS (2009) Role of heat shock protein 27 phosphorylation in migration of vascular smooth muscle cells. Mol Cell Biochem 327: 1-6

Ciocca DR, Calderwood SK (2005) Heat shock proteins in cancer: diagnostic, prognostic, predictive, and treatment implications. Cell Stress Chaperones 10: 86-103

de Kok JB, Roelofs RW, Giesendorf BA, Pennings JL, Waas ET, Feuth T, Swinkels DW, Span PN (2005) Normalization of gene expression measurements in tumor tissues: comparison of 13 endogenous control genes. Lab Invest 85: 154-159

El Hilali N, Rubio N, Martinez-Villacampa M, Blanco J (2002) Combined noninvasive imaging and luminometric quantification of luciferaselabeled human prostate tumors and metastases. Lab Invest 82: 1563-1571

Garrido C, Fromentin A, Bonnotte B, Favre N, Moutet M, Arrigo AP, Mehlen P, Solary E (1998) Heat shock protein 27 enhances the tumorigenicity of immunogenic rat colon carcinoma cell clones. Cancer Res 58: 5495-5499
(Gibert et al, 2011). These results are in correlation with our presented data because proliferation is not modified in the in vitro context, whereas B02-Sh27 tumour growth was altered in vivo. It is thus tempting to propose that Hsp27 may have an important role in protecting bone cells against these kinds of stress (Muraoka et al, 2010).

Altogether, these results support the view that Hsp27 has a crucial role during metastasis and tumour implementation and expansion in the bone. Targeting Hsp27 may then prove to be a promising strategy to prevent bone metastasis, which is a terrible step towards patient death.

\section{ACKNOWLEDGEMENTS}

This work was supported by a research grant from the Comité du Rhône of la Ligue Contre le Cancer and by the Region Rhône-Alpes. BG post doctoral fellowship is supported by ARC.

\section{Conflict of interest}

The authors declare no conflict of interest.

Supplementary Information accompanies the paper on British Journal of Cancer website (http://www.nature.com/bjc)

Gibert B, Eckel B, Fasquelle L, Moulin M, Bouhallier F, Gonin V, Mellier G, Simon S, Kretz-Remy C, Arrigo AP, Diaz-Latoud C (2012) Knock down of heat shock protein 27 (HspB1) induces degradation of several putative client proteins. PLoS One 7: e29719

Gibert B, Hadchity E, Czekalla A, Aloy MT, Colas P, Rodriguez-Lafrasse C, Arrigo AP, Diaz-Latoud C (2011) Inhibition of heat shock protein 27 (HspB1) tumorigenic functions by peptide aptamers. Oncogene 30: 3672-3681

Huang Q, Ye J, Chen W, Wang L, Lin W, Lin J, Lin X (2010) Heat shock protein 27 is over-expressed in tumor tissues and increased in sera of patients with gastric adenocarcinoma. Clin Chem Lab Med 48: 263-269

Javouhey E, Gibert B, Arrigo AP, Diaz JJ, Diaz-Latoud C (2008) Protection against heat and staurosporine mediated apoptosis by the HSV-1 US11 protein. Virology 376: 31-41

Jaya N, Garcia V, Vierling E (2009) Substrate binding site flexibility of the small heat shock protein molecular chaperones. Proc Natl Acad Sci USA 106: $15604-15609$

Kaur P, Nagaraja GM, Asea A (2011) Combined lentiviral and RNAi technologies for the delivery and permanent silencing of the hsp25 gene. Methods Mol Biol 787: 121-136

Lee JW, Kwak HJ, Lee JJ, Kim YN, Park MJ, Jung SE, Hong SI, Lee JH, Lee JS (2008) HSP27 regulates cell adhesion and invasion via modulation of focal adhesion kinase and MMP-2 expression. Eur J Cell Biol 87: 377-387

Lee YJ, Cho HN, Jeoung DI, Soh JW, Cho CK, Bae S, Chung HY, Lee SJ, Lee YS (2004) HSP25 overexpression attenuates oxidative stress-induced apoptosis: roles of ERK1/2 signaling and manganese superoxide dismutase. Free Radic Biol Med 36: 429-444

Lemieux P, Harvey J, Guise T, Dallas M, Oesterreich S, Yin J, Selander K, Fuqua S (1999) Low cell motility induced by hsp27 overexpression decreases osteolytic bone metastases of human breast cancer cells in vivo. J Bone Miner Res 14: 1570-1575

Mehlen P, Schulze-Osthoff K, Arrigo AP (1996) Small stress proteins as novel regulators of apoptosis. Heat shock protein 27 blocks Fas/APO-1and staurosporine-induced cell death. J Biol Chem 271: 16510-16514

Muraoka D, Kato T, Wang L, Maeda Y, Noguchi T, Harada N, Takeda K, Yagita H, Guillaume P, Luescher I, Old LJ, Shiku H, Nishikawa H (2010) Peptide vaccine induces enhanced tumor growth associated with apoptosis induction in CD8 + T cells. J Immunol 185: 3768-3776

Park SH, Lee YS, Osawa Y, Hachiya M, Akashi M (2002) Hsp25 regulates the expression of $\mathrm{p} 21$ (Waf1/Cip1/Sdi1) through multiple mechanisms. J Biochem 131: 869-875 
Paroo Z, Bollinger RA, Braasch DA, Richer E, Corey DR, Antich PP, Mason RP (2004) Validating bioluminescence imaging as a high-throughput, quantitative modality for assessing tumor burden. Mol Imaging 3: 117-124

Paul C, Manero F, Gonin S, Kretz-Remy C, Virot S, Arrigo AP (2002) Hsp27 as a negative regulator of cytochrome C release. Mol Cell Biol 22: 816-834

Paul C, Simon S, Gibert B, Virot S, Manero F, Arrigo AP (2010) Dynamic processes that reflect anti-apoptotic strategies set up by HspB1 (Hsp27). Exp Cell Res 316: 1535-1552

Pecheur I, Peyruchaud O, Serre CM, Guglielmi J, Voland C, Bourre F, Margue C, Cohen-Solal M, Buffet A, Kieffer N, Clezardin P (2002) Integrin alpha(v)beta3 expression confers on tumor cells a greater propensity to metastasize to bone. FASEB J 16: 1266-1268

Peyruchaud O, Serre CM, NicAmhlaoibh R, Fournier P, Clezardin P (2003) Angiostatin inhibits bone metastasis formation in nude mice through a direct anti-osteoclastic activity. J Biol Chem 278: 45826-45832

Pivovarova AV, Chebotareva NA, Chernik IS, Gusev NB, Levitsky DI (2007) Small heat shock protein Hsp27 prevents heat-induced aggregation of F-actin by forming soluble complexes with denatured actin. FEBS J 274: 5937-5948

Song HY, Liu YK, Feng JT, Cui JF, Dai Z, Zhang LJ, Feng JX, Shen HL, Tang ZY (2006) Proteomic analysis on metastasis-associated proteins of human hepatocellular carcinoma tissues. J Cancer Res Clin Oncol 132: 92-98

Tian T, Hao J, Xu A, Luo C, Liu C, Huang L, Xiao X, He D (2007) Determination of metastasis-associated proteins in non-small cell lung cancer by comparative proteomic analysis. Cancer Sci 98: 1265-1274

Tsuruta M, Nishibori H, Hasegawa H, Ishii Y, Endo T, Kubota T, Kitajima M, Kitagawa Y (2008) Heat shock protein 27, a novel regulator of 5-fluorouracil resistance in colon cancer. Oncol Rep 20: 1165-1172
Venkatakrishnan CD, Tewari AK, Moldovan L, Cardounel AJ, Zweier JL, Kuppusamy P, Ilangovan G (2006) Heat shock protects cardiac cells from doxorubicin-induced toxicity by activating p38 MAPK and phosphorylation of small heat shock protein 27. Am J Physiol Heart Circ Physiol 291: H2680-H2691

Voss OH, Batra S, Kolattukudy SJ, Gonzalez-Mejia ME, Smith JB, Doseff AI (2007) Binding of caspase-3 prodomain to heat shock protein 27 regulates monocyte apoptosis by inhibiting caspase-3 proteolytic activation. J Biol Chem 282: 25088-25099

Wei L, Liu TT, Wang HH, Hong HM, Yu AL, Feng HP, Chang WW (2011) Hsp27 participates in the maintenance of breast cancer stem cells through regulation of epithelial-mesenchymal transition and nuclear factor-kappaB. Breast Cancer Res 13: R101

Workman P, Aboagye EO, Balkwill F, Balmain A, Bruder G, Chaplin DJ, Double JA, Everitt J, Farningham DA, Glennie MJ, Kelland LR, Robinson V, Stratford IJ, Tozer GM, Watson S, Wedge SR, Eccles SA (2010) Guidelines for the welfare and use of animals in cancer research. Br I Cancer 102: 1555-1577

Wyttenbach A, Sauvageot O, Carmichael J, Diaz-Latoud C, Arrigo AP, Rubinsztein DC (2002) Heat shock protein 27 prevents cellular polyglutamine toxicity and suppresses the increase of reactive oxygen species caused by huntingtin. Hum Mol Genet 11: 1137-1151

Zhang Y, Shen X (2007) Heat shock protein 27 protects L929 cells from cisplatin-induced apoptosis by enhancing Akt activation and abating suppression of thioredoxin reductase activity. Clin Cancer Res 13: 2855-2864

Zhao Y, Bachelier R, Treilleux I, Pujuguet P, Peyruchaud O, Baron R, Clement-Lacroix P, Clezardin P (2007) Tumour alphavbeta3 integrin is a therapeutic target for breast cancer bone metastases. Cancer Res 67: 5821-5830

This work is published under the standard license to publish agreement. After 12 months the work will become freely available and the license terms will switch to a Creative Commons Attribution-NonCommercial-Share Alike 3.0 Unported License. 